\title{
Screening for Cervical Cancer by Visual Inspection with Acetic Acid (VIA) in Nabil Choucair Health Center-Dakar (Senegal)
}

\author{
Babacar Biaye*, Omar Gassama, Marie Édouard Faye Dieme, Youssoupha Touré, Mor Cissé, \\ Mouhamadou Wade, Daba Diop, Bakhoum Assane, Mamour Gueye, Abdoul Aziz Diouf, \\ Jean Charles Moreau
}

Gynecological and Obstetric Clinic, University Hospital Aristide Le Dantec, Dakar, Senegal

Email: *drbabacarbiaye@yahoo.fr

How to cite this paper: Biaye, B., Gassama, O., Faye Dieme, M.E., Toure, Y., Cisse, M., Wade, M., Diop, D., Assane, B., Gueye, M., Diouf, A.A. and Moreau, J.C. (2019) Screening for Cervical Cancer by Visual Inspection with Acetic Acid (VIA) in Nabil Choucair Health Center-Dakar (Senegal). Open Journal of Obstetrics and Gynecology, 9, 302-311.

https://doi.org/10.4236/ojog.2019.93031

Received: January 29, 2019

Accepted: March 1, 2019

Published: March 4, 2019

Copyright $\odot 2019$ by author(s) and Scientific Research Publishing Inc. This work is licensed under the Creative Commons Attribution International License (CC BY 4.0).

http://creativecommons.org/licenses/by/4.0/

\begin{abstract}
OBJECTIVES: 1) To draw up the epidemiological profile of patients who have benefited from cervical cancer screening by visual inspection after application of acetic acid (VIA) and then describe the results of the test, the colposcopy, histological and therapeutic aspects in case of dysplasia. 2) To evaluate the performance of IVA in cervical cancer screening and its feasibility in low-resource countries. MATERIALS AND METHODS: This was a prospective and descriptive study carried out from 06 June 2015 to 31 January 2016 (7 months) at the Maternity Center at Nabil Choucair health center in Dakar. The patients had been screened for cervical cancer by visual inspection, which consisted of applying 3\% acetic acid after setting up a vaginal speculum. The test was considered positive if there were intense white areas in the cervix. Colposcopy was performed in case of a positive VIA result. This colposcopy included an unprepared examination, an examination after application of 3\% acetic acid and an examination after application of Lugol solution. The colposcopic report is made according to the terminology of the French Society of Colposcopy and Cervico-Vaginal Pathology. Patients with major changes or unsatisfactory colposcopy had undergone diathermic loop resection. Surgical specimens were sent to pathologic anatomy and follow-up was performed according to the results of the histology. The studied parameters concerned the socio-demographic aspects, the results of the VIA test, the results of the colposcopy after a positive test, the therapeutic aspects in case atypical transformation zone grade 2 or of unsatisfactory colposcopy, the results of the histology after the conization and the followed. The collection of data was done thanks to a file and the statistical analysis thanks to the software Epi-info version 7. RESULTS: 899 patients were involved in the study.
\end{abstract}


The epidemiologic profile of our patient was a multipara in a period of genital activity, aged 42.2 years with a mean gestational weight of 4.5 , and a parity of 4. In our series, the patients had their first sexual intercourse with 20.8 years old. In our study, 84 patients (10.2\%) had positive results after visual inspection after acetic acid applications. All patients with positive results after application of 3\% acetic acid had colposcopy. In our study, 27 patients had major changes and/or unsatisfactory colposcopy and underwent diathermic loop resection for diagnostic and therapeutic purposes. Anatomo-pathological examination of the cone room revealed cervicitis in $22.2 \%$ of cases, flat condyloma in $7.4 \%$ of cases, CIN2 in $22.2 \%$ of cases, and CIN 3 in $18.5 \%$ of cases. All the conizations were in sano. The postoperative course was simple. CONCLUSION: Cervical cancer is a real public health problem in developing countries. To do to human resources, developing countries like Senegal must put in place simple, inexpensive, effective strategies that must globally respond to "screen and treat".

\section{Keywords}

Cervical Cancer Screening, VIA, Colposcopy, Dysplasia, Diathermic Loop Conization

\section{Introduction}

Cervical cancer is a public health problem. This condition is responsible for more than 500,000 new cases and more than 265,000 deaths a year worldwide. This high incidence and mortality occur in $85 \%$ of cases in developing countries, especially those in sub-Saharan Africa [1].

In Senegal, there are 1800 new cases of cervical cancer each year and 795 deaths [2].

These figures are alarming if compared to the Senegalese population, which is estimated at 14 million inhabitants [2].

Cervical cancer is a preventable cancer because of its accessibility to screening [1] [2] [3] [4].

The human papillomavirus (HPV) is a very important factor in the occurrence of cervical cancer. Oncogenic strains, high-risk (HR-HPV), are the main risk factors for cervical cancer. The duration of HR-HPV infection has been associated with the development of transient, persistent, or cancer-prone intraepithelial precancerous lesions [5] [6]. The period between the first cytological abnormalities and the possible appearance of invasive cancer is estimated to be around ten years. Preventive vaccines, currently available on the market, are particularly targeted at HR-HPV 16 and 18 [7]. However, immunosuppression and sexually transmitted infections would potentiate the action of oncogenic strains of HPV [8]. Other factors such as high parity and poor socio-economic conditions also contribute to the development of cervical dysplasia [9]. Cervical cancer can be prevented by the screening and treatment of precancerous lesions 
[10]. A woman undergoing cervical cancer screening, between the ages of 30 and 40 , would see her risk of developing cervical cancer reduced by $25 \%$ to $36 \%$.

The effectiveness of cervical-vaginal smear screening has been proven in industrialized countries because it has drastically reduced the incidence and mortality of cervical cancer [1] [3] [4] [11].

Visual inspection of the cervix after application of acetic acid (VIA) is a simple, affordable cervical cancer screening approach that is particularly relevant to the realities of developing countries [12]. VIA has the advantage of screening for operable pre-cancerous and cancerous cervical lesions with comparable and sometimes better sensitivity than that of FCV. According to African studies, the sensitivity of the VIA test varies from $79 \%$ to $97 \%$ with a specificity between $87 \%$ and $96 \%$ [13] [14].

For the prevention of cervical cancer, developing countries have almost no screening program and are faced with lack of infrastructure, lack of staff. To this lack of personnel and infrastructure are added poverty and lack of education for populations who are risk factors for cervical cancer [4] [5] [11]. As a result, simple and accessible screening strategies such as visual inspection after acetic acid should be encouraged.

The main objective of this study is to evaluate the performance of IVA in cervical cancer screening and its feasibility in low-resource countries.

\section{Materials and Methods}

This was a prospective and descriptive study conducted at the Nabil Choucair Health Center maternity center in Dakar, Senegal, from June 06, 2015 to January 31, 2016 (7 months).

Included in this study were all women who had come for cervical cancer screening and who had given consent after days of awareness about the disease.

The patients had been screened for cervical cancer by visual inspection, which consisted of applying $3 \%$ acetic acid after setting up a vaginal speculum. The test was considered positive if there were intense white areas in the cervix. Colposcopy was performed in case of a positive VIA result. This colposcopy included an unprepared examination, an examination after application of 3\% acetic acid and examination after application of Lugol solution. The colposcopic report is made according to the terminology of the French Society of Colposcopy and Cervico-Vaginal Pathology. Colposcopy is said to be unsatisfactory if the junction area is not visible.

Patients with major changes or unsatisfactory colposcopy had undergone diathermic loop resection. Surgical specimens were sent to pathologic anatomy and follow-up was performed according to the results of the histology. The parameters studied included socio-demographic aspects, gynecological obstetrical history,

VIA test results, colposcopy results after a positive test, therapeutic aspects in the case atypical transformation zone grade 2 or unsatisfactory colposcopy, the results of the study. Histology after conization and follow-up.

Sensitivity, specificity, negative predictive value, positive predictive value of 
visual inspection after application of $3 \%$ acetic acid were also assessed.

These last parameters were calculated by taking colposcopy as a reference test.

The epidemiological parameters were obtained thanks to a data collection form completed by the participants.

The capture is made thanks to the software Sphinx and the statistical analysis by the software Epi-info 3.5 .

\section{Results}

\subsection{Socio-Demographic Characteristics}

During our study period, we recorded 899 patients.

The epidemiologic profile of our patient was a multipara in a period of genital activity, aged 42.2 years with a mean gesture of 4.5 and an average parity of 4 . In our series, all the patients were married and had their first sexual intercourse at 21 years old.

A proportion of 774 patients $(86.1 \%)$ were in a period of genital activity and constituted the major part of our series.

\subsection{Visual Inspection after Application of 3\% Acetic Acid}

Visual inspection after application of acetic acid was positive in 84 patients $(10.2 \%)$ and was negative in 815 of our patients.

\subsection{Colposcopy}

Colposcopy was performed in 84 patients (10.2\%) who had a positive VIA test.

On examination without preparation, we found a pink collar in 68 patients $(81.3 \%)$ and a red collar in 16 patients (18.7\%). At the end of the examination, colposcopy had shown an atypical transformation zone grade 2 in $19.4 \%$ of cases (Table 1).

\subsection{Diathermic Loop Resection}

In our study 27 patients (32.1\%) had grade II atypical transformation and/or unsatisfactory colposcopy and underwent diathermic loop resection under local $5 \%$ xylocaine anesthesia without epinephrine \%. This conization to the diathermic loop was performed for diagnostic and therapeutic purposes.

\subsection{Results of the Anatomopathological Examination of the Conization Piece}

Histological examination of the cone chamber revealed a high grade of cervical intraepithelial neoplasia (CIN3) in $18.5 \%$ of cases and CIN1 in $22.2 \%$ of cases (Table 2). All the conizations were in sano.

\subsection{Performance of Visual Screening Methods for Cervical Cancer (VIA)}

In our series we found a sensitivity of $100 \%$ (Table 3 ). 
Table 1. Distribution of patients the conclusion of colposcopy.

\begin{tabular}{ccc}
\hline Colposcopic Conclusion & Number(n) & Percentage (\%) \\
\hline Normale & 35 & $41.7 \%$ \\
Cervix inflammation & 9 & $10.3 \%$ \\
Atypical transformation zone grade 2 & 13 & $15.5 \%$ \\
Atypical transformation zone grade 2 & 16 & $19.4 \%$ \\
Unsatisfactory colposcopy & 11 & 13.1 \\
Total & $\mathbf{8 4}$ & 100 \\
\hline
\end{tabular}

Table 2. Distribution of the patients according to the results of the histological examination after a conization with the diathermic loop.

\begin{tabular}{ccc}
\hline Histological results & number & $\%$ \\
\hline Chronic cervicitis & 6 & 22.2 \\
Cervical polyp & 2 & 7.4 \\
Condyloma plane & 2 & 7.4 \\
Endo-cervicitis & 5 & 18.5 \\
CIN1 & 1 & 3.7 \\
CIN2 & 6 & 22.2 \\
CIN3 & 5 & 18.5 \\
Total & 27 & 100 \\
\hline
\end{tabular}

Table 3. Performance of the VIA Screening Test.

\begin{tabular}{ccccc}
\hline & Sensibility $\%$ & Specificity $\%$ & PPV $\%$ & NPV \% \\
\hline VIA & 100 & 92 & 37.2 & 98 \\
\hline
\end{tabular}

PPV: positive predictive value; NPV: negative predictive value.

\subsection{Follow Up}

At 6 months of follow-up, in our series visual inspection by visual inspection after application of a $3 \%$ solution of acetic acid followed by colposcopy did not find any abnormalities in the patients having undergone a cone biopsy.

\section{Discussion}

\subsection{Limitations of the Study}

The IVA tests were performed by several gynecologists. It is obvious that not all practitioners can have the same experience in interpreting tests. The other limitation is that we have not explored the HIV status of our patients.

\subsection{Socio-Demographic Characteristics}

Cervical cancer is a real public health problem because of the high incidence and mortality attributable to it, which is high in developing countries. 
Developing countries are characterized by a lack of screening program and strategy. We conducted a pilot study by visual inspection of the uterine cervix after application of acetic acid at the Nabil Choucair Health Center in urban Dakar, Senegal to assess the feasibility of the test.

In our study, the average age of patients was 42.2 years with extremes of 18 years and 75 years and (44.7\%) were between 35 and 55 years old. Our average age was lower than those found by Dembele [15] in Dakar, Tebeu [16] in rural Cameroon and by Surendra [17] in India where the average age was 44, 46 and 44.84 years respectively. The consideration of organized screening at a young age is crucial given the incidence and mortality of cervical cancer in developing countries characterized by the lack of a screening program [17].

Screening programs vary from country to country. In South Africa, a national cervical cancer screening program was initiated with the goal of performing cervical and cervical Pap smear testing at 3 years of age from 30 years of age [18].

In Cuba, a screening program was set up in 1968 and more than $80 \%$ of women aged between 20 and 60 had been cared for [19].

In the USA, screening is performed from the age of 20; it is the same in the Scandinavian countries as Iceland while it is done in France for the first time between 25 and 65 years old [20]. To harmonize screening programs, WHO has recommended that new screening programs first offer testing to women over 30 years of age and then to younger women once coverage of the high-risk group is reached is assured. WHO also advocates not including women under 25, and prioritizing screening for women aged 30 - 49. This screening should be continued until the age of 65 provided that the two previous smears are negative [4] [21] [22].

Cervical cancer is an "infectious disease" caused by human papillomaviruses with a socio-economic connotation related to co-factors such as poverty, early marriage, early intercourse, and multiparity, which affect women in their youth [1]-[6] [11] [12].

The epidemiologic profile of our patient was a multiparous during a period of genital activity with a mean gesture of 4.5 and an average parity of 4 . In our series all the patients were married and had their first sexual intercourse at 20.8 years old. A correlation between the age of first intercourse and the occurrence of cervical cancer was established. The adolescent's cervix is both more exposed to infections and more vulnerable because of the physiological eversion of the glandular mucosa (monolayer epithelium more exposed to the gaps allowing the entry of the virus) [9] [12].

Indeed, the earlier it occurs, the higher the chances of developing cancer, it is called a window of vulnerability, predominant before the age of 20 years. Some authors also mention the high number of sexual intercourse per week as a factor of aggravation of the risk of HPV involvement and therefore of cervical cancer. Spousal sexual behavior also seems decisive. Some studies have found a linear relationship between male sexual behavior and rates of HPV infection in women with cervical cancer. It appears that women whose spouses have multiple sexual 
partners are more likely to develop cervical cancer [12].

Some authors consider gestationality as a cofactor related to uncontrolled sexual activity, or unplanned maternity [23].

Others, on the other hand, consider that gestationality is a risk factor in its own right, implying the physiological impact of the evolution of pregnancy on the mechanisms of local immune defenses linked to the biological upheaval experienced by the cervical epithelium uterus [18].

\subsection{Screening for Cervical Cancer}

Screening for cervical cancer with IVA is one of the proposed methods proposed in resource limited countries by the World Health Organization [3] [4] [5] [24] [25].

The VIA at the Nabil Choucair Health Center showed a positive test for 84 patients (10.2\%). The positivity rate of visual tests for cervical cancer screening varies by country and is variously reported in the literature. Dangou [14] found a rate of 5.4\% in Guinea, Kabibou [21] and Sankanaryanan [12] found at the rate of $6.81 \%$ in Benin and $16.1 \%$ in a multicenter study in India and in Africa, Moukassa [23] in Congo recovered at a rate of $15.36 \%$. These disparities are explained by the socio-demographic and cultural variations of the different populations but also by the experience of the providers.

\subsection{Colposcopy}

Colposcopy is an angular examination for the diagnosis of dysplasias of the cervix [17] [19].

In our study 84 patients (10.2\%) had benefited from colposcopy.

Colposcopy recovered anmajor changes and/or was unsatisfactory for $27 \mathrm{pa}$ tients.

The performance of colposcopy is operator-dependent. The colposcopist may have difficulty assessing an atypical Grade II transformation lesion and immature metaplastic images.

Indeed, two processes as different as immature metaplasia, which is a repair process, and severe dysplasia, which is a proliferative process, can generate quite similar colposcopy features. These difficulties diminish with the practice of colposcopy [26].

\subsection{Electro-Resection at the Diathermic Loop}

Therapeutic options for dysplasia are cryotherapy or diathermic loop electro resection in resource-limited settings.

The Senegalese population is characterized by a high birth rate with a relatively young age for the first pregnancies, multiple pregnancies, the modest socio-economic level of women without empowerment and poor compliance for follow-up [27] [28]. These different parameters were the arguments that led us to choose as a therapeutic strategy a conization to the diathermic loop. This 
Table 4. Performance of VIA.

\begin{tabular}{ccccccc}
\hline Study & Year & Country & Sensitivity \% & Spécificity \% & PPV \% & NPV \% \\
\hline Our study & 2016 & Sénégal & 100 & 92 & 37.2 & 98 \\
Mpiga1 [29] & 2015 & Gabon & 88.89 & 100 & 100 & 92.3 \\
Sankarnarayanan [30] & 2012 & Inde & 80 & 92 & 10 & 99 \\
Fofana [31] & 2003 & Burkina Faso & 95 & 98.2 & 86.4 & 99.5 \\
Gaffikin [32] & 2003 & USA & 96 & 97 & 20 & 95 \\
\hline
\end{tabular}

conization was made for diagnostic and therapeutic purposes. All pieces of conization were sent to the laboratory of Anatomy and Pathology Cytology of Aristide Le Dantec University Hospital. Histological examination in our series found a CIN2 in $22.2 \%$ of cases.

\subsection{Performance of VIA}

Screening for cervical cancer by VIA has a very good performance with sensitivity ranging from $80 \%$ to $96 \%$ [29] [30] [31] [32].

In our study we found a sensitivity of $100 \%$, a specificity of $92 \%$, a positive predictive value of $37.2 \%$ and a negative predictive value of $100 \%$.

Compared to other studies done elsewhere like that Sankarnarayanan [30] and Gaffikin [32], we find our rate sensitivity, specificity and positive and negative predictive values were more high (Table 4). This can be explained by the fact that they had hundreds of thousands of patients in their cohort unlike ours, which is a small cohort.

Screening for cervical cancer by IVA remains an opportunity to be seized in developing countries.

\section{Conclusions}

Cervical cancer is a public health problem in Senegal. Like other developing countries, Senegal faces shortages of infrastructure, resources and other public health priorities such as maternal and child mortality.

This study shows that efforts must be made to set up a simple screening method based on:

- Visual inspection after application of acetic acid;

- In the case of a positive test, use colposcopy;

- In the case of atypical Grade 2 transformation or unsatisfactory colposcopy, a diathermic loop resection is proposed.

\section{Conflicts of Interest}

The authors declare no conflicts of interest regarding the publication of this paper.

\section{References}

[1] Ferlay, J., Soerjomataram, I., Dikshit, R., Eser, S., Mathers, C., Rebelo, M., et al. 
(2015) Cancer Incidence and Mortality Worldwide: Sources, Methods and Major Patterns in GLOBOCAN 2012. International Journal of Cancer, 136, E359-E386. https://doi.org/10.1002/ijc.29210

[2] ICO (Institut Català Oncologia) Information Centre on HPV and Cancer Sénégal (2014) Human Papillomavirus and Related Cancers Fact Sheet.

[3] Organisation Mondiale de la Santé (2013) Note d'orientation de l'OMS Approcheglobale de prévention et de luttecontre le cancer du col de l'utérus: Versunemeilleure santé pour les femmes et les filles. Departement de priseen charge des maladies non transmissibles, $16 \mathrm{p}$.

[4] Organisation Mondiale de la Santé (2015) Lignesdirectrices de l'OMS pour le dépistageet le traitement des lésionsprécancéreuses pour la prévention du cancer du col de l'utérus, $62 \mathrm{p}$.

[5] Zur Hausen, H. (1996) Papillomavirus Infections a Major Cause of Human Cancers. Biochimica et Biophysica Acta, 1288, F55-F78. https://doi.org/10.1016/0304-419X(96)00020-0

[6] Bosch, F.X., Lorincz, A., Munoz, N., Meijer, C.J. and Shah, K.V. (2002) The Causal Relation between Human Papillomavirus and Cervical Cancer. Journal of clinical pathology, 55, 244-265. https://doi.org/10.1136/jcp.55.4.244

[7] Dochez, C., Bogers, J.J., Verhelst, R. and Rees, H. (2014) HPV Vaccines to Prevent Cervical Cancer and Genital Warts: An Update. Vaccine, 32, 1595-1601. https://doi.org/10.1016/j.vaccine.2013.10.081

[8] Castle, P.E. and Giuliano, A.R. (2003) Chapter 4: Genital Tract Infections, Cervical Inflammation, and Antioxidant Nutrients Assessing Their Roles as Human Papillomavirus Cofactors. Journal of the National Cancer Institute. Monographs, 31, 29-34. https://doi.org/10.1093/oxfordjournals.jncimonographs.a003478

[9] Bayo, S., Bosch, F.X., de Sanjosé, S., Muñoz, N., Combita, A.L., Coursaget, P., et al. (2002) Risk Factors of Invasive Cervical Cancer in Mali. International Journal of Epidemiology, 31, 202-209. https://doi.org/10.1093/ije/31.1.202

[10] WHO (2007) La luttecontre le cancer du col de l'utérus: Guide des pratiquesessentielles. OMS, Genève.

[11] JHPIEGO an Affiliate of Johns Hopkins University (2016) Prévention du cancer du col de l'utérus. Guide pratique pour les milieux à ressourcesfaibles.

http://www.jhpiego.org

[12] Sankaranarayanan, R., Basu, P., Wesley, R.S., Mahe, C., Keita, N., Mbalawa, C.C., et al. (2004) Accuracy of Visual Screening for Cervical Neoplasia: Results from an IARC Multicentre Study in India and Africa. International Journal of Cancer, 110, 907-913. https://doi.org/10.1002/ijc.20190

[13] University of Zimbabwe, JHPIEGO Cervical Cancer Project (1999) Visual Inspection with Acetic Acid for Cervical Cancer Screening: Test Qualities in Primary-Care Setting. Lancet, 353, 869-873. https://doi.org/10.1016/S0140-6736(98)07033-0

[14] Dangou, J.M., Keïta, N. and Mbaye, K. (2012) Prévention et management du cancer du col de l'utérusen Guinée Konakry. African Health Monitor, 15, 214-223.

[15] Dembélé, B. (2006) Dépistage et priseen charge des néoplasiescervicales intra-épithéliales du col utérin à l'Institut Curie de Dakar: Etude pilote. Thése, Medicine, Dakar, No. 53.

[16] Tebeu, P.M. (2005) Lésionsprécancereuses du col utérinen zone rurale: Étudetransversale. Medicine Afrique Noire, 52, 27-31.

[17] Surendra, S.S., Indraneel, M., Gauravi, A.M., Subhadra, G., Rajesh, D., et al. (2014) 
Effect of VIA Screening by Primary Health Workers; Randomized Controlled Study in Mumbia, India. Journal of the National Cancer Institute, 106, 1-7.

[18] Monsonego, J. (2006) Infections à human papillomavirus: Etats des connaissances, pratiques et préventionvaccinale. Springer, Paris.

[19] Miller, A. and Nazeer, S. (2000) Report on Consensus Conference on Cervical Cancer Screening and Management. International Journal of Cancer, 86, 440-447. https://doi.org/10.1002/(SICI)1097-0215(20000501)86:3<440::AID-IJC22>3.0.CO;2-A

[20] Fender, M., Schaffer, P. and Dellenbach, P. (1998) Peut-on et faut-ilorganiser le dépistage du cancer du col de l'utérusen France? Journal de Gynécologie Obstétrique et Biologie de la Reproduction, 27, 683-691.

[21] Kabibou, S., Luc, B., Akpona, L.F.J. and Perrin, R.X. (2015) Facteursassociés aux lésionsprécancéreuses et cancéreuses du col de l'utérus au CHU de Parakou au Benin. European Scientific Journal, 11, 1857-1881.

[22] Organisation Mondiale de la Santé (2007) Contextegénéral. In: Laluttecontre le cancer du col de P utérus, Guide des pratiquesessentielles, OMS, Genève, 15-26.

[23] Moukassa, D. (2007) Lésionsprécancereuses du cancer du col de l'utérus à Pointe Noire: Analyse de situation. MedTrop, 67, 57-60.

[24] Agence Nationale de la Statistiqueet de la Démographie (Sénégal) (2013) Enquête Démographiqueet de Santé à Indicateurs multiples au Sénégal (EDS-MICS) 2012-2013. Calverton, Maryland, 262 p.

[25] Huchko Megan, J., et al. (2014) Comparaison de deuxméthodesd'inspectionvisuelle pour le dépistage du cancer du col de l'utérus chez les femmes infectées par le VIH au Kenya. Bulletin de l'organisationmondiale de la santé, 94,195-203.

[26] Marshall Austin, R. and Ramzy, I. (1998) Increased Detection of Epithelial Cell Abnormalities by Liquid-Based Gynecologic Cytology Preparations. A Review of Accumulated Data. Acta Cytologica, 42, 178-184. https://doi.org/10.1159/000331543

[27] Baldauf, J.J., Baulon, E., Thoma, V., Woronoff, A.S. and Akladios, C.Y. (2013) Conséquences Obstétricales des conisations à l'anse diathermique et facteurs aggravants. Journal Gynécologie Obstétrique et Biologie de la Reproduction, 42, 534-540.

[28] Sangwa-Lugoma, G., Salaheddin, M., Samih, H., Jean, L., Kayembe, P.K., Rahma, R. and Pierre, D. (2006) Visual Inspection as a Cervical Cancer Screening Method in a Primary Health Care Setting in Africa. International Journal of Cancer, 119, 1389-1395. https://doi.org/10.1002/ijc.21972

[29] Mpiga, É., Ivanga, M. and Koumakpay, I.H. (2015) Intérêt de l'inspectionvisuelle à l'acideacétiqueet au soluté de Lugol avec colposcopedans le dépistage des lésions du col utérin au Gabon. Pan African Medical Journal, 12, 1-6.

[30] Sankarnarayanan, R., Nessa, A., Esmy, P.O., et al. (2012) Visual Inspection Methods for Cervical Cancer Prevention. Best Practice \& Research: Clinical Obstetrics \& Gynaecology, 26, 221-232. https://doi.org/10.1016/j.bpobgyn.2011.08.003

[31] Fofana, M. (2003) Depistageprecoce des lesions precancereuses du col uterin au burkinafaso: Etude comparative de I1nspection visuelle après application dacideacétique (IVA) et de soluté de/ugol (IVL). Thése Med., No. 142.

[32] Gaffikin, L., Lauterbach, M. and Blumenthal, P.D. (2003) Performance of Visual Inspection with Acetic Acid for Cervical Cancer Screening: A Qualitative Summary of Evidence to Date. Obstetrical and Gynaecological Review, 58, 543-550. 